\title{
ANÁLISE DO TRATAMENTO DE ÁGUA E ESGOTO NO ESTADO DO TOCANTINS
}

\author{
Paulo R. Sousa' \\ Rafael M. S. Oliveira² \\ Aurelio P. Picanço ${ }^{3}$
}

Resumo: As questões ligadas ao saneamento do meio ainda são um grande desafio para a melhoria da saúde pública da população. Dados demonstram que o Brasil possui graves problemas nessa área principalmente nas relacionadas a gestão de resíduos sólidos e coleta e tratamento de esgotos sanitários. Essa ultima atinge mais de $50 \%$ da população do país as quais não possuem sistema de coleta e de disposição de esgoto, e quando possuem sistemas de disposição muitas vezes esses não possuem adequação técnica para tal. O estado do Tocantins não foge a regra o estado possui cerca de $85 \%$ da população sem rede de esgoto. Na maioria das cidades a disposição e feita em fossas negras, inadequadas ambientalmente e legalmente para a disposição, essas cidades em sua grande maioria não possui caminhão limpa fossa e os excrementos dos moradores são dispostos nessas fossas e absorvidos pelo solo. Este estudo demonstra a atual situação do tratamento de água e sistema de coleta e tratamento de esgoto do Estado do Tocantins.

Palavras-chave: Saneamento. Esgoto sanitário. Estado do Tocantins

\section{INTRODUÇÃO}

A água é importante por ser essencial ao ser humano, ao desenvolvimento econômico e à preservação do meio ambiente. Para atender as necessidades fisiológicas é preciso ingeri, em média de 2 a 3 litros de água por dia, embora o consumo per capita míni- 
mo necessário para manter uma boa saúde, por meio da higiene pessoal e da preparação de alimentos, seja de 100 litros por dia (VASCONCELOS, JÚNIOR, et al., 2008).

Os esgotos são os despejos provenientes dos diversos usos da água. Esgotos sanitários são despejos constituídos de águas residuárias de uso doméstico e industrial e as águas de infiltração. Esgotos domésticos - a parcela mais significativa dos esgotos sanitários - são provenientes principalmente de residências e edificações públicas e comerciais que concentram aparelhos sanitários, lavanderias e cozinhas(BRAGA, HESPANHOL, et al., 2005, p. 118).

A quantidade de esgoto produzido pode variar bastante de uma comunidade para outra, ou até mesmo dentro de uma mesma comunidade em função de diversos fatores. A "qualidade" dos esgotos varia em função da composição da água de abastecimento e dos diversos usos. De modo geral podemos dizer que os esgotos sanitários são constituídos de99,9\%de líquidos (água) e 0,1\% de sólidos, em peso.(BRAGA, HESPANHOL, et al., 2005, p. 119).

Como consequência da explosão demográfica nos centros urbanos brasileiros e das mudanças nos padrões de consumo na segunda metade do século $X X$, aumentou-se 0 consumo de água em até seis vezes na primeira metade da década de 90, gerando aumento na demanda por infraestrutura de saneamento do meio(MALHEIROS, 2005, p. 183).

O Sistema Nacional de Informações sobre Saneamento (SNIS) é constituído pelos serviços de água, esgotos, manejo de resíduos sólidos e de qualidade dos serviços (BRASIL, 2012, p. 07).

Para água e esgotos, as informações são fornecidas por companhias estaduais, autarquias municipais, empresas privadas e, em muitos casos, pelas próprias prefeituras. Os dados permitem identificar, com elevado grau de objetividade, os aspectos da gestão dos respectivos serviços nos municípios brasileiros(BRASIL, 2012, p. 07).

O diagnóstico do ano de 2010 agregou informações sobre abastecimento de água em 4.952 municípios e sobre esgotamento sanitário em 2.734 municípios, que correspon- 
dem a $97,7 \%$ e $85,3 \%$, respectivamente, da população urbana do país (BRASIL, 2012, p. 07).

O Estado do Tocantins possui uma população total de 1.383.453habitantes, tendo Produto Interno Bruto (PIB) total de $R \$ 17.240 .000,00$, e per capita de $\mathrm{R} \$ 12.461,64$, conforme (IBGE, 2010).

A fito ecologia do Estado do Tocantins é constituída por Cerrado, Floresta Estacional, Floresta Ombrófila e regiões de tenção ecológica Estacional/Ombrófila, Cerrado/Estacional e Cerrado/Ombrófila (SEPLAN, 2012).É constituído com dois grandes sistemas hidrográficos, dos rios Araguaia e Tocantins com áreas de 104.971,8 km² e $172.828,2 \mathrm{~km}^{2}$, respectivamente. Apresentando duas estações bem definidas, uma chuvosa de outubro a maio e outra seca de junho a setembro, com temperatura média anual variando entre 25 e $27^{\circ} \mathrm{C}$,(SEPLAN, 2012).

Segundo o SNIS no ano de 2010, foram atendidas no Estado do Tocantins 1.017.404 habitantes com água tratada, somando um volume de $43.258 .580 \mathrm{~m}^{3}$ de água, e 187.672 habitantes com tratamento de esgoto, somando um volume de $6.509 .760 \mathrm{~m}^{3}$ de esgoto.

O objetivo deste estudo foi analisar a evolução do saneamento no Estado do Tocantins a partir das informações disponibilizadas pelo SNIS, do Ministério das Cidades, Instituto Brasileira de Geografia e Estatística (IBGE), Agência Tocantinense de Saneamento (ATS) e/ou prestadores de serviços em saneamento nos municípios tocantinenses, tendo como referência a ano de 2010, em decorrência da disponibilidade de informações.

\section{MATERIAIS E MÉTODOS}

Este projeto foi desenvolvido conforme as seguintes etapas: levantamento bibliográfico; análise a avaliação das informações levantadas; descrição dos resultados obtidos; e proposição de recomendações. Abaixo estão descritas cada umas das quatro fases. 
Na primeira etapa foram levantadas informações gerais sobre a situação do tratamento e da distribuição de água e coleta e tratamento de esgoto sanitário no Estado do Tocantins. Os dados foram obtidos junto ao SNIS, IBGE, ATS, Secretária de Planejamento do Estado do Tocantins (SEPLAN), e das operadoras/prestadoras de serviços de saneamento do Estado.

Posteriormente foram classificados os principais indicadores, aqueles que ao serem analisados pudessem expressar as necessidades básicas com relação ao saneamento ambiental para garantir saúde e qualidade de vida a população tocantinense.

$\mathrm{Na}$ segunda etapa os indicadores selecionados foram avaliados para apontarem a real condição dos serviços de tratamento de água e esgoto sanitário prestados à população tocantinense. Cada indicador foi classificado como sendo A, B, C, D e E, se apresentou índice de atendimento igual ou menor que 100\%, $80 \%, 60 \%, 40 \%$ e $20 \%$, respectivamente.

Na terceira etapa foram descritos os resultados obtidos e realizada argumentações e discussões, aferindo os principais índices e indicadores que caracterizassem da melhor forma a situação do saneamento ambiental no Estado do Tocantins. Os resultados foram descritos (item 03) satisfazendo a seguinte ordem de exposição: i) tratamento e distribuição de água; coleta e tratamento de esgoto; e perfil dos prestadores de serviços.

$\mathrm{Na}$ quarta e última etapa foram feitas recomendações e proposições acerca das conclusões obtidas pelo processo de análise realizado.

\section{RESULTADOS E DISCUSSÕES}

O Estado do Tocantins possui 06 prestadores de serviços de tratamento e distribuição de água, sendo 01 município atendido pela administração pública direta, 03 por autarquias, 118 por empresa privada e 11 não foram obtidas informações. 
O gráfico 01 demonstra que o volume de água tratada acompanha o volume de água produzida, com exceção dos anos de 2004, 2005 e 2006, onde os dados indicam maior volume de água tratada.

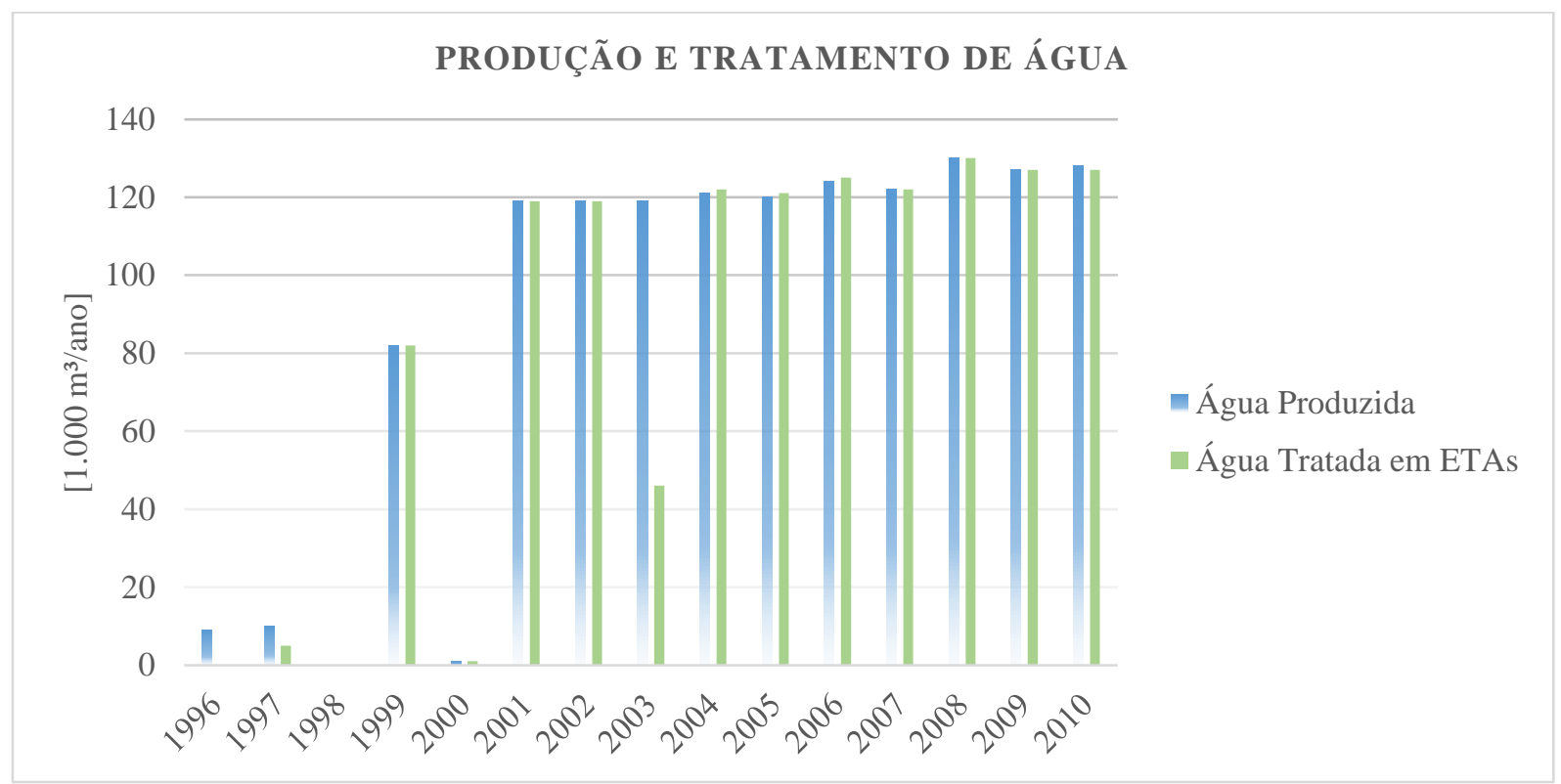

Todo o Estado produziu 76.375,03 mil m³ de água em 2010, sendo Palmas e Araguaína as cidades com maior quantidade de água produzida, sendo $17.752,45 \mathrm{mil} \mathrm{m}^{3} \mathrm{e}$ $11.085,06$ mil m$^{3}$, respectivamente.

Já com relação ao tratamento de água para o referido ano, o Tocantins tratou 43.258,58 mil m³ de água, com índice percentual de 73,54\% (situação B) para o Estado, sendo Palmas e Paraíso do Tocantins as cidades que apresentaram maior índice percentual, $82,47 \%$ e $93,24 \%$ (situação A), respectivamente. 


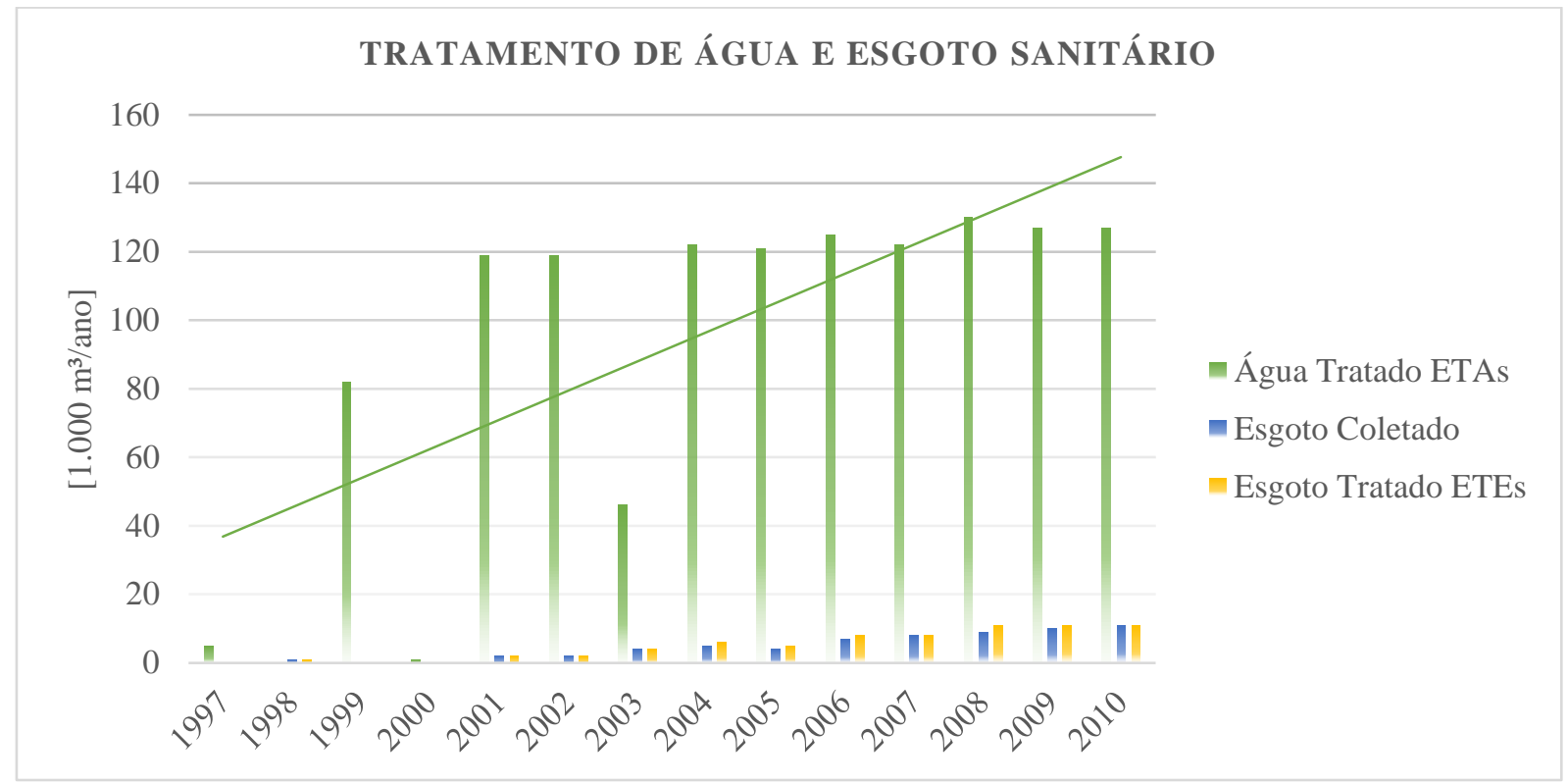

O consumo per capita do ano de referência, considerando água consumida e a população atendida foi de 139,10 L/hab./dia, conforme (BRASIL, 2012). Tendo como destaque as cidades de Ananás e Muricilândia do Tocantins com o maior e o menor consumo per capita, 428,40 L/hab./dia e 80,30 L/hab./dia, respectivamente.

O gráfico 3 apresenta o consumo médio per capita com relação a água tratada para a série histórica no Estado desde 2004. Observando a linha de tendência verifica-se que é menos inclinada do que a linha de tendência para o tratamento de água (gráfico 2), expressando que o volume de água tratada tem crescido mais que o consumo médio per capita, o que significa que tem aumentado também a população atendida neste período. 


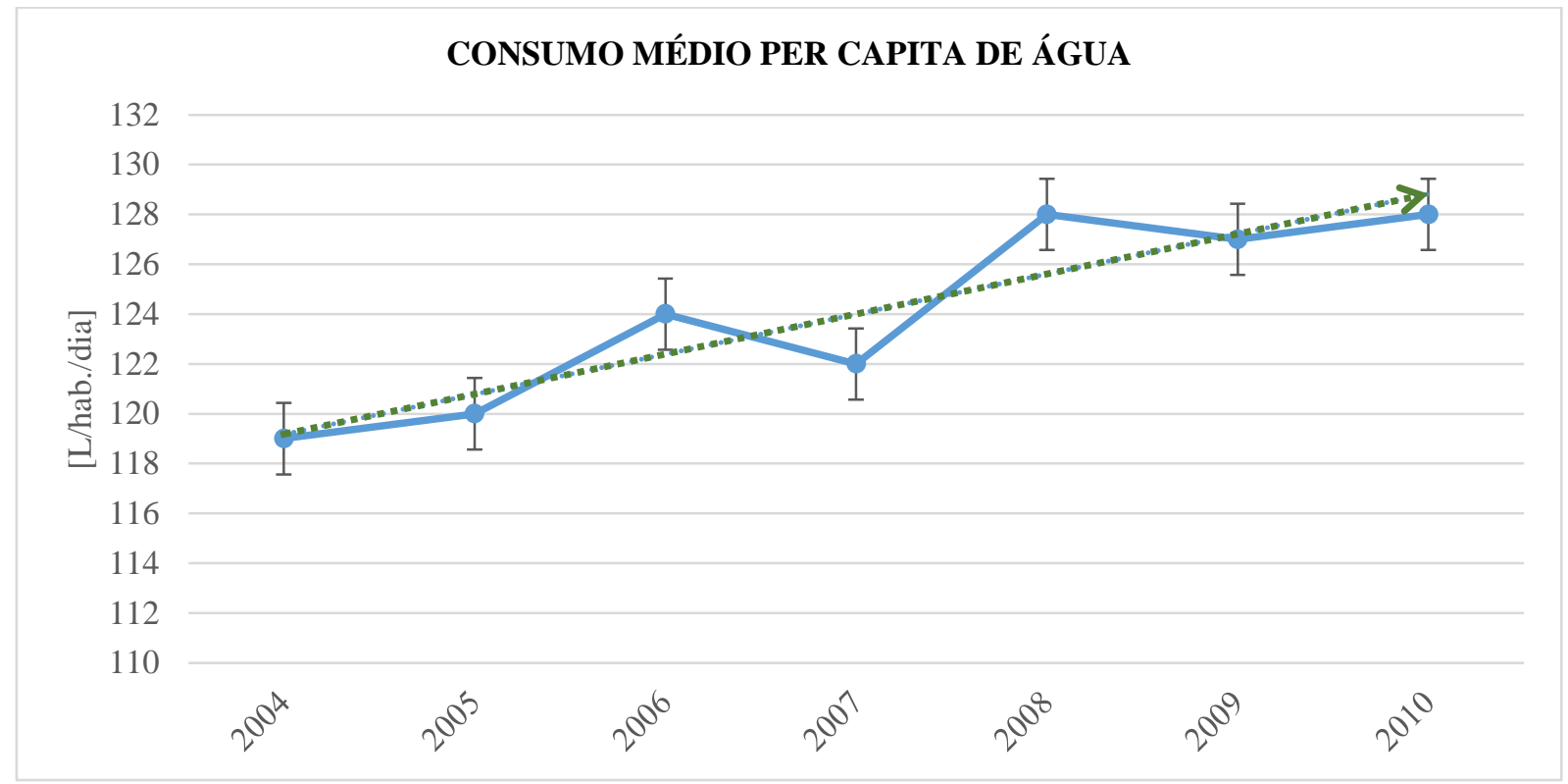

\section{ESGOTO}

Com relação a coleta e tratamento de esgoto, verificou-se situação semelhante com os prestadoras de serviços, sendo as mesmas 06 que operam os sistemas de tratamento e distribuição de água, com 01 municípios atendido pela administração pública direta, 02 por autarquias, 10 por empresa privada, 11 não obtidas informações e 104 não possuem sistemas de coleta e tratamento de esgoto, utilizando fossas sépticas ou dispondo aleatoriamente no solo seus dejetos e resíduos.

Para o ano de referência a população total atendida com coleta e tratamento de esgoto sanitário foi de 193.997 habitantes, com 56.191 ligações de esgoto distribuídas em 1.055,96 Km de rede coletora de esgoto sanitário, sendo de 127,12 m, a extensão da rede por ligação (BRASIL, 2012).

O gráfico 02 , correlaciona a coleta e o tratamento de esgoto no Estado, demostrando que $100 \%$ do esgoto coletado é conduzido para processos de tratado adequados.

Por outro lado, conforme análise dos dados do SNIS, ainda não são coletados e tratados cerca de $95,34 \%$ do esgoto produzido considerando os anos com informações dis- 
ponibilizadas pelo SNIS, 2001 a 2010, e a taxa de retorno de 80\%, conforme média considerado pelas companhias de saneamento como índice percentual para a formação do valor de cobrança pelo serviço de tratamento de esgoto.

\section{AGUA E ESGOTO}

O gráfico 04 , mostra a curva para o tratamento de água para a coleta e tratamento de esgoto com o número de municípios e as variações entre as condições $A$ a $E$. No caso do tratamento de água foram classificados como A, B, C e D; 24, 52, 44 e 08 municípios respectivamente. Já para a coleta e tratamento de esgoto foram classificados como C, D, e E; 01, 05, e 122 municípios, respectivamente.

A linha de tendência do polinomial demonstra o comportamento do tratamento de água e coleta e tratamento de esgoto

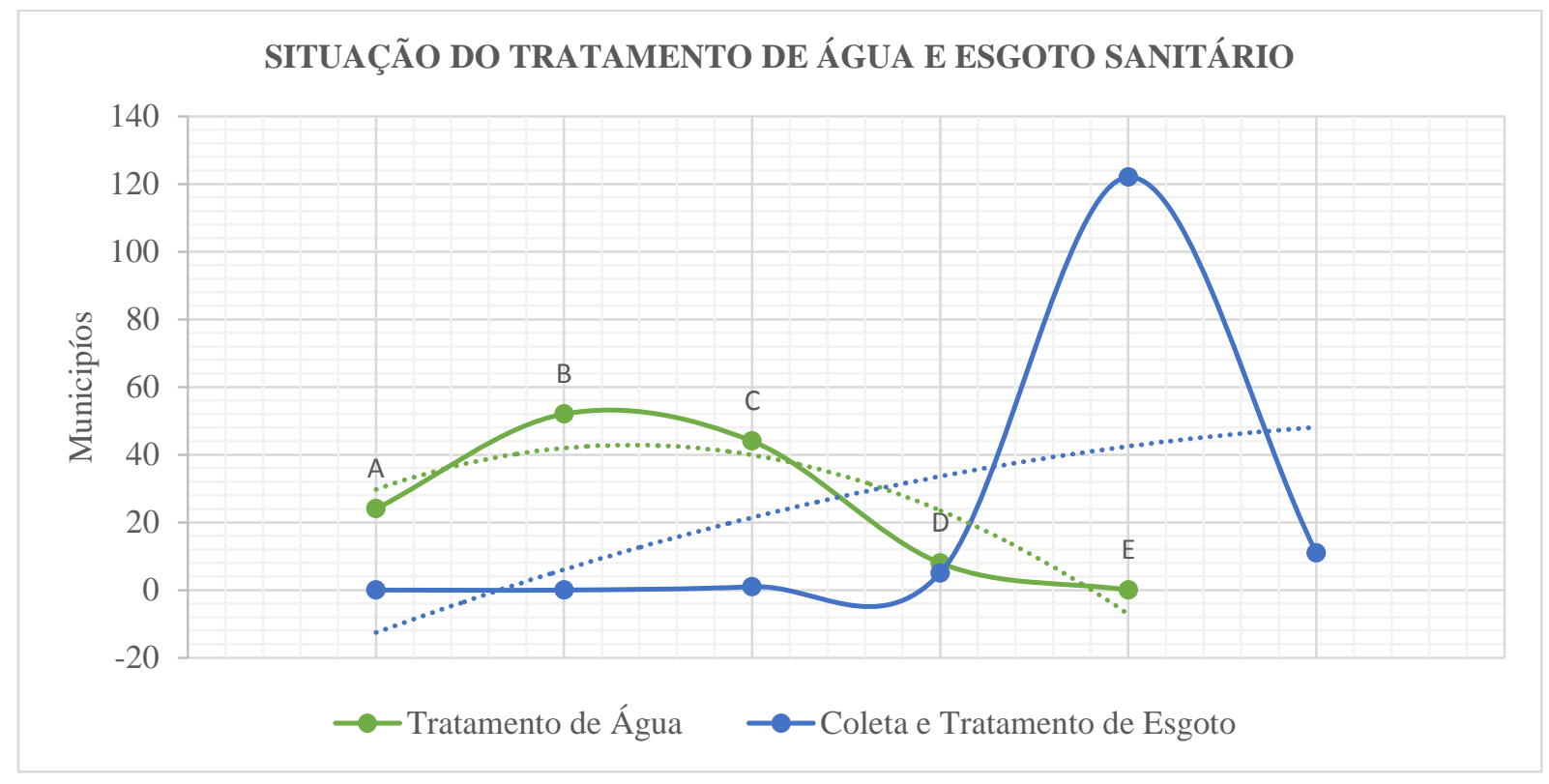

PERFIL

No Estado do Tocantins existem 06 prestadoras de serviços em saneamento ambiental, nos próximos parágrafos encontra-se descrito o perfil de cada uma delas com seus 
principais índices relacionados ao tratamento e distribuição de água e a coleta e tratamento de esgoto. As informações relacionadas a indicadores e índices são alusivas ao ano de referência do estudo, sendo os dados fornecidos pelo SNIS e pelos próprios prestadores de serviços.

O Serviço Autônomo de Água e Esgotos (SAAE), é uma prestadora de serviços em saneamento de abrangência local que atende o município de Ananás com os serviços de tratamento de distribuição de água e coleta e tratamento de esgotos. É ligada a administração pública direta com natureza jurídica constituída como autarquia.

O SAAE, atende uma população total de 8.384 habitantes com tratamento e distribuição de água, com volume total de água tratada de $110.000 \mathrm{~m}^{3} / \mathrm{mês}$, rede de distribuição de $78 \mathrm{Km}$ de extensão (26,6 m/ligação), disponibilizando $37,5 \mathrm{~m} 3 / \mathrm{mês} / \mathrm{economia} \mathrm{atra-}$ vés de 2.931 ligações, sendo 2.240 ativas para o ano de referência.

Com relação a coleta e tratamento de esgoto atende uma população total de 2.152 habitantes, com tratamento de $1.874,16 \mathrm{~m}^{3}$ de esgoto por mês, representando $1,7 \%$ do volume de água tratada pela companhia. Possui $36 \mathrm{Km}$ de rede coletora de esgotos de 541 ligações com distância de68,57 m, entre as ligações.

Outro prestador de serviços que atual no Estado do Tocantins é o Serviço Municipal de Água e Esgoto (SEMAE), que é de abrangência local e atende o município de Itacajá com os serviços de tratamento de distribuição de água e coleta e tratamento de esgotos sanitário. Esta também é ligada a administração pública direta possui natureza jurídica constituída como autarquia.

O SEMAE, atende uma população total de 4.273 habitantes com tratamento e distribuição de água, com volume total de água tratada de $11.666 \mathrm{~m}^{3} / \mathrm{mês}$, rede de distribuição de 16,55 Km de extensão (9,7 m/ligação), disponibilizando 10,4 m³/mês/economia através de 1.695 ligações, sendo 1.443 ativas para o ano de referência.

Para a coleta e tratamento de esgoto sanitário atende uma população total de 1.445 habitantes, com tratamento de $3.375 \mathrm{~m}^{3}$ de esgoto por mês, representando $24,55 \%$ do volume de água tratada pela companhia. Possui $15,91 \mathrm{Km}$ de rede coletora de esgotos com 1.062 ligações com distância de 14,98 m entre as ligações. 
A Companhia de Saneamento do Tocantins (SANEATINS), é empresa privada do grupo foz Odebrecht, constituindo atualmente a maior operadora de serviços em saneamento do Estado do Tocantins e a única que atende no Estado e é de abrangência regional, atende 128 municípios com tratamento e distribuição de água e 10 municípios com coleta e tratamento de esgoto sanitário. Os municípios com maior demanda pelos serviços de saneamento no Estado são atendidos pela SANEATINS, sendo Palmas, Araguaína e Gurupi, com 218.806, 112.316; 138.316, 19.160; e 70.089, 17.851 habitantes, com tratamento e distribuição de água e coleta e tratamento de esgoto, respectivamente.

A SANEATINS, atende uma população total de 1.035 .573 habitantes com tratamento e distribuição de água, com volume total de água tratada de $3.433 .476,67 \mathrm{~m} 3 / \mathrm{mês}$, rede de distribuição de 7.108,91 Km de extensão (17,30 m/ligação), disponibilizando 19,10 m³/mês/economia através de 2.931 ligações, sendo 2.240 ativas para o ano de referência.

A cobertura dos serviços de coleta e tratamento de esgoto sanitário executados pela SANEATINS abrangem uma população total de 190.000 habitantes, com tratamento de $573.115 \mathrm{~m}^{3}$ de esgoto por mês, representando $14,05 \%$ do volume de água tratada pela companhia. Possui $990,78 \mathrm{Km}$ de rede coletora de esgotos com 54.063 ligações com distância de 18,69 m entre as ligações.

O quarto prestador de serviços é a Prefeitura Municipal de Pedro Afonso (PMPA), é de abrangência local e atende o município de Pedro Afonso com o serviço de tratamento de distribuição de água, e é ligada a administração pública direta.

A PMPA atende uma população total de 10.016 habitantes com tratamento e distribuição de água, com volume total de água tratada de 122.666,67 m³/mês, rede de distribuição de $35 \mathrm{Km}$ de extensão (9,60 m/ligação), disponibilizando $34,40 \mathrm{~m}$ 3/mês/economia através de 3.566 ligações. A PMPA não presta serviços de coleta e tratamento de esgotos.

O próximo prestador de serviço que abordamos é o Serviço Autônomo de Água e Esgoto (SAAE), é uma prestador de serviços em saneamento de abrangência local que 
ISSN 1980-0827

Volume 9, Número 11, 2013

Saúde, Saneamento e

Meio Ambiente

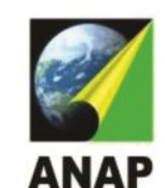

ANAP

atende o município de Santa Fé do Araguaia com os serviços de distribuição de água. É ligada a administração pública direta com natureza jurídica constituída como autarquia.

O SAAE, de Santa Fé do Araguaia atende uma população total de 3.800 habitantes com distribuição de água em $15 \mathrm{Km}$ de rede de distribuição (7,80 m/ligação)através de 1.596 ligações, sendo 1.174 ativas para o ano de referência. O SAAE, não presta serviços de coleta e tratamento de esgoto.

A última prestadora de serviços que abordamos é a empresa privada Hidroforte Administração e Operação LTDA (HAO), que de abrangência local que atende o município de Talismã com os serviços de tratamento de distribuição de água e coleta e tratamento de esgotos.

A HAO, atende uma população total de 1.663 habitantes com tratamento e distribuição de água, com volume total de água tratada de $666,67 \mathrm{~m} 3 / \mathrm{mês}$, rede de distribuição de $23 \mathrm{Km}$ de extensão (28,80 m/ligação), disponibilizando $20 \mathrm{~m} 3 / \mathrm{mês} /$ economia através de 875 ligações, sendo 590 ativas para o ano de referência.

Já para a coleta e tratamento de esgoto atende uma população total de 400 habitantes, com tratamento de $2.000,00 \mathrm{~m}^{3}$ de esgoto por mês, representando $18,18 \%$ do volume de água tratada pela companhia. Possui $13 \mathrm{Km}$ de rede coletora de esgotos de 525 ligações com distância de 24,88 m entre as ligações. 


\section{CONCLUSÕES}

$\checkmark$ Cerca de $20 \%$ da população tocantinense, 250.000 habitantes aproximadamente ainda não tem acesso a tratamento e abastecimento de água;

$\checkmark$ Da mesma forma cerca de $85 \%$ da população tocantinense, quase 1.000 .000 habitantes ainda não tem acesso a coleta e tratamento de esgoto;

\section{REFERÊNCIAS BIBLIOGRÁFICAS}

BRAGA, B. et al. Introdução a Engenharia Ambiental. 2a . ed. São Paulo: Pearson Prentice Hall, 2005. 318 p.

BRASIL. diagnóstico dos serviços de água e esgoto - 2010. Brasília: Sistema Nacional de Saneamento Ambiental - Secretaria Nacional de Saneamento Ambiental, 2012. 448 p.

IBGE. Censo Populacional 2010. Instituto Brasileiro de Geografia e Estatística: Brasilía, DF, 2010.

MALHEIROS, T. F. Águas Residuárias: Visão de Saúde Pública e Ambiental. In: JN., A. P. Saneamento, Saude e Ambiente. Barueri: Manole, 2005. 842 p.

SEPLAN. Atlas do Tocantins. Palmas: Secretaria de Planejamento do Estado do Tocantins, 2012. $80 \mathrm{p}$.

VASCONCELOS, I. C. D. et al. Esgotamento Sanitário: qualidade da água e controle da poluição. Salvador: Secretaria Nacional de Saneamento Ambiental, 2008. 87 p. 